\title{
Expectativas e usos de uma biblioteca escolar
}

\author{
Expectations and uses of school library
}

\author{
Caio Henrique Almeida ${ }^{1}$ \\ Simone Meucci ${ }^{2}$
}

\begin{abstract}
Resumo
$\mathrm{O}$ artigo tem como objetivo confrontar expectativas e usos da biblioteca escolar. O texto divide-se em tem duas partes. Na primeira, consultamos textos e documentos cujo tema são biblioteca escolares. Constatamos, em suas páginas, muitas esperanças, dificuldades, desafios e tarefas depositadas na biblioteca escolar, entendida como importante locus de ensino e aprendizagem. Na segunda parte, descrevemos a biblioteca de uma escola pública de Curitiba -PR e cotejamos dados acerca do fluxo de empréstimo. Observamos que a biblioteca escolar em questão é subutilizada. A direção da escola, por outro lado, não a representa como um lugar cujas tarefas exigem tratamento profissional e cujos horários devem se apresentar como alternativa de estudos após o fim ou início das aulas. No que tange aos empréstimos, verificamos que, a cada ano escolar, o interesse pelo acervo se reduz. $\mathrm{Na}$ conclusão, exploramos alguns fatores escolares, organizacionais e sociais que podem explicar o fenômeno em questão.
\end{abstract}

Palavras-chave: Expectativas. Usos. Empréstimos. Biblioteca escolar.

\begin{abstract}
s
The article aims to confront expectations and uses of school library. The text is divided in two parts. At first, we consult texts and documents whose theme is school library. We found, in its pages, many hopes, difficulties, challenges and tasks deposited in the school library, understood like an important locus of learning. In the second part, we describe the library of a public school in Curitiba - PR highlighting data about the books lending. We note that the school library is rarely used by students. The direction of this school, on the other hand, don't require professional workers for the tasks in the school library and alternatively hours after the end or beginning of classes. About the loans of books, we find that, every school year, the interest for students about the library increases. In

\footnotetext{
${ }^{1}$ Graduado em licenciatura e bacharelado em Ciências Sociais pela Universidade Federal do Paraná (UFPR). Trabalhou como bolsista CAPES do Programa Institucional de Bolsa de Iniciação à Docência (PIBID) do curso de Ciências Sociais da UFPR (2011 -2014). Trabalhou como professor de Sociologia no ensino público do Paraná, SEED - PR (2015-2017). Atualmente e mestrando do Programa de Pós-Graduação em Sociologia pela UFPR. E-mail: caiohtc@gmail.com.

2 Doutora em Sociologia pela Universidade de Campinas (Unicamp) e Professora adjunta (em regime de Dedicação Exclusiva) do Departamento de Ciências Política e Sociologia da Universidade Federal do Paraná (UFPR).Email: deciso@ufpr.br.
} 
conclusion, we explore some organizational, educational and social factor that can explain the phenomenon in question.

Keywords: Expectations. Uses. Loans. School library.

\begin{abstract}
"E livro para quê, minha filha! O que é o livro? É uma invenção sobre as pessoas. Até o romance é um disparate, $e$ escrito para um disparate, só para que as pessoas ociosas possam ler acredite em mim, minha filha, acredite em minha experiência de muitos anos. E olha lá, se vierem atordoa-la com um tal de Shakespeare, dizendo, está vendo, na literatura há Shakespeare - pois saiba que Shakespeare também é um disparate, tudo isso é puro disparate, e tudo feito unicamente para pasquinada!" (Dostoiévski, Gente Pobre, 2009, p.106.)
\end{abstract}

"Aprender a escrever (e a ler) é descobrir uma nova representação do mundo que modifica, em contrapartida, as maneiras de pensar e de conceber as trocas no âmbito da linguagem". (Anne-Marie Chatier, 1995, p.38.)

As atividades do PIBID (Programa Institucional de Incentivo à Docência) de Ciências Sociais da UFPR (Universidade Federal do Paraná) possibilitaram que acompanhássemos as condições de estudo e sociabilidade de jovens e as práticas profissionais de professoras e professores em algumas escolas públicas de Curitiba - PR.

Isso favoreceu a análise do cotidiano escolar e inspirou a formulação de indagações acerca do modo como as relações sociais, a ocupação e uso dos espaços escolares produz sentidos e efeitos da escola na vida de estudantes, técnicos e técnicas, zeladores e zeladoras, professoras e professores. De início, durante as primeiras observações, procuramos identificar espaços escolares que estudantes, servidoras e servidores mais frequentavam, como também os lugares subutilizados.

Dessa observação geral resultou uma inquietação que assumiu contornos mais objetivos na forma de uma sondagem, desenvolvida em 2014, originalmente apresentada para uma disciplina optativa da graduação, cujas considerações são descritas neste artigo. A investigação teve como objeto a biblioteca escolar, entendendo-a como um lugar revelador das possibilidades e limites para o êxito da escola na transmissão de certos hábitos de estudo. Indagamos acerca do uso do espaço da biblioteca e de seu acervo pelos estudantes da escola. 
A análise que apresentaremos compreende duas etapas: a) consulta a textos e documentos que ajudam perscrutar significados e justificar ações em favor da implantação e aquisição de acervos para bibliotecas escolares; b) descrição do espaço e levantamento dos registros de empréstimos numa escola pública estadual localizada em Curitiba, Paraná. Nosso objetivo foi, a partir de um caso, confrontar expectativas e usos da biblioteca escolar para, com isso, fecundar novas hipóteses para pesquisas futuras acerca do tema.

\section{A importância da biblioteca escolar: manifestos, leis e ações}

No caso particular das bibliotecas escolares, observamos que documentos de numerosas instituições lhe atribuem importância pedagógica central. De acordo com o Manifesto da IFLA/ UNESCO para Biblioteca Escolar (2002) escrito com a intenção de fundamentar uma estratégia global para o desenvolvimento e valorização de bibliotecas em escolas de diversos países. A biblioteca escolar é responsável por disponibilizar informações fundamentais para estudantes desenvolverem habilidades de aprendizado e aperfeiçoarem a imaginação.

A missão da biblioteca escolar, segundo a UNESCO, seria a promoção de serviços de apoio à aprendizagem, influenciando a elevação do desempenho dos estudantes na leitura e escrita, favorecendo a formação de pensadores críticos usuários da informação em diversos formatos e meios. A biblioteca escolar é, pois, entendida como um espaço onde podem ocorrer vivências decisivas para um aprendizado significativo, resultante do manuseio de ferramentas de consulta ao acervo dos conhecimentos considerados socialmente relevantes para a constituição de indivíduos autônomos.

No Brasil, de acordo Ferrarezi e Romão (2013), documentos oficiais recentes, "Biblioteca escolar: tudo começa aqui"; "Manifesto em Defesa da Biblioteca Escolar" e a "Carta de Brasília em Defesa da Biblioteca Escolar" denotam a produção de um discurso acerca da biblioteca escolar estão afinados com as orientações da IFLA/Unesco (2002). 
Estes documentos possuem uma marca linguística que se caracteriza pela recorrência de verbos que ensejam as potencialidades da biblioteca no ambiente escolar: "promove”, “influencia”, “incentiva”, “viabiliza”, “estimula”, "organiza", "trabalhar e "atua". Palavras frequentes que se referem à potencialidade da biblioteca escolar provocar uma experiência intelectual considerada decisiva para autonomia do estudante. (FERRAREZI \& ROMÃO, 2013, p.10).

Damasceno e Mesquita (2013, p. 151) argumentam que a biblioteca escolar pode ter também outros sentidos e tarefas que ultrapassam a fronteira da escola. De acordo com seus argumentos, a biblioteca escolar teria também a potencialidade de desenvolver a interação com a comunidade em que está inserida, configurando-se como um espaço possivel de socialização do conhecimento capaz de dinamizar a cultura da localidade. Dessa forma, seu espaço de ensino e aprendizado ultrapassa as fronteiras da escola e, oferecese como uma opção à comunidade local, configurando-se como uma expectativa sobre a sua utilização.

Com efeito, são muitas as expectativas em relação à biblioteca escolar que se manifestam em diversos documentos e artigos. Essas expectativas se expressam também em ações sistemáticas. E ainda que, no Brasil, a Lei de Diretrizes e Bases da Educação (LDB), aprovada em 1996, sequer mencione a biblioteca escolar, houve, no final dos anos 1990 uma iniciativa importante no reconhecimento da necessidade de ampliação do acervo de livros nas escolas: a criação do Programa Nacional da Biblioteca Escola (PNBE), dedicado à avaliação e aquisição de livros para as escolas. Uma política pública de grandes dimensões tanto em recursos quanto em abrangência.

A propósito, numa breve retrospectiva pode-se observar que especialmente ao longo dos anos 2000 várias iniciativas de valorização e fomento à leitura surgiram no Brasil por iniciativa do Estado. Citamos como exemplo a criação do Plano Nacional do Livro e Leitura (PNLL), a criação da Câmara Setorial do Livro, do Instituto Pró-livro e do Observatório do livro e da leitura, entre outras ações que tinham como objetivo a democratização ao acesso a livros e o incentivo à leitura (LAJOLO, 2012, p.165). 
O PNBE, em particular, é um programa financiado e executado pelo Fundo Nacional de Desenvolvimento da Educação (FNDE) em parceria com a Secretaria de Educação Básica do Ministério da Educação (SEB-MEC) com o objetivo de promover o acesso à cultura, o incentivo à leitura e o apoio pedagógico e didático a professores e alunos através da aquisição de obras de excelência para o Ensino Público em todas as suas esferas: municipal, estadual e federal. Seu embrião foram os programas Pró-Ler e Pró-Leitura, desenvolvidos em 1992.

Atualmente, o PNBE está divido em três frentes para a aquisição de livros: PNBE do Professor, PNBE Periódicos, o PNBE Temático e o PNBEM Programa Nacional Biblioteca da Escola para o Ensino Médio. ${ }^{3}$ A distribuição dos livros para as escolas segue um cronograma fixo anual e a seleção dos títulos é feita por uma equipe formada por professores e professoras de universidades federais, possuindo um limite máximo de títulos que podem ser selecionados. Se analisarmos os dados finais do PNBE de 2013 - quando a distribuição de livros foi feita para os anos final do Ensino Fundamental e para o Ensino Médio - encontraremos resultados expressivos: foram distribuídos 7.426.531 livros, divididos em 360 títulos.

No entanto, apesar dos investimentos surpreendentes do PNBE e sua implantação desde o final dos anos de 1990, apenas em 2010 surgiu uma lei específica obrigando, em tempo máximo de 10 anos, que cada escola tenha espaço físico adequado para sua coleção de livros, materiais videográficos e documentos registrados em qualquer suporte destinados a consulta, pesquisa, estudo ou leitura. (BRASIL, 2010) Trata-se de uma meta desejável, mas rigorosamente inexequível considerando que, segundo dados do Censo Escolar, o Brasil tem um déficit de 128 mil unidades, o que exigiria a construção de 39 bibliotecas escolares por dia. ${ }^{4}$

E ainda que exista espaço físico adequado, outro fenômeno incômodo desafia o cumprimento das expectativas depositadas sobre a biblioteca escolar: a sua subutilização. Frequentemente, são ambientes vazios, quando

\footnotetext{
${ }^{3}$ Fonte: MINISTÉRIO DA EDUCAÇÃO/FNDE

${ }^{4}$ Fonte: MINISTÉRIO DA EDUCAÇÃO/INEP
} 
não inacessiveis por cumprirem a função de depósito de materiais de consumo e equipamentos sucateados.

Não se trata de um consolo, mas é importante lembrar que a subutilização das bibliotecas escolares não é um fenômeno exclusivo de escolas brasileiras, tampouco limitado aos estudantes. A baixa frequência dos professores nas bibliotecas das escolas públicas de Portugal é tema de estudo de Balça e Fonseca (2012) no qual se constata que os docentes possuem uma visão clara sobre a importância da biblioteca escolar, mas não a utilizam efetivamente.

Com efeito, são fenômenos contraditórios: a enorme importância atribuída à biblioteca escolar e sua subutilização. Disso surgiu nosso interesse por esta investigação que consiste em compreender as condições de uso de uma escola de Ensino Fundamental e Ensino Médio de Curitiba - PR. Para isso, realizamos uma análise do espaço, verificamos o acervo bibliográfico disponivel, ao mesmo tempo em que identificamos através de consulta aos cadernos de registros de entrada e saída de livros. Veremos que os dados nos apontam sugestões interessantes acerca de mudanças no comportamento dos estudantes em relação ao empréstimo de livros ao longo dos anos de formação escolar.

É preciso, no entanto, observar que essa pesquisa resultou em dados muito modestos que inspiram muitas perguntas e hipóteses para o desenvolvimento de pesquisas futuras.

\section{A escola, a biblioteca e os livros}

O Colégio Estadual Pedro Macedo de Ensino Fundamental, Médio e Profissional está localizado na cidade de Curitiba - PR, num bairro que, de acordo com os dados do Instituto de Pesquisa e Planejamento Urbano de Curitiba (IPPUC), possui 42.662 habitantes. 5

O bairro fica numa área importante e valorizada, próxima ao centro da cidade e de fácil acesso, bem servido de vias rápidas e linhas de ônibus. ${ }^{6} \mathrm{O}$

\footnotetext{
${ }^{5}$ Curitiba tem 1.751.907 habitantes, segundo dados do IPPUC de 2014.

6 FONTE: CURITIBA/ IPPUC.
} 
colégio é um ponto de encontro estrutural, por causa dessa particularidade. O que acaba diversificando o seu corpo de estudantes.

É também uma região com muitas escolas. Segundo dados do Censo Escolar da Secretária da Educação (SEED-PR) em 2012 o bairro contava com 22 escolas municipais com 11.018 crianças matriculadas, e três escolas estaduais com 2.226 matrículas. O Colégio Pedro Macedo é o mais importante dentre eles, tem boa infraestrutura e goza do status de ser uma das melhores escolas públicas da cidade. O Índice de Desenvolvimento da Educação Básica (IDEB) do ano de 2013 foi de 6,0 pontos em contraste com a média das escolas da cidade que é de 4,1 .

De acordo com seu Projeto Político Pedagógico (PPP) a escola tem de 2.599 alunos e alunas distribuídos nos turnos da manhã, tarde e noite. O turno da manhã são 462 que cursam o Ensino Médio e 261 o Ensino Profissionalizante. No período da tarde são 542 que frequentam regularmente o Ensino Fundamental, 82 o Médio e 42 o Ensino Profissionalizante. Finalmente, no período noturno são 188 cursando o Ensino Médio, 41 no Profissional Integrado e 363 estão matriculados no Ensino Profissional Subsequente, conhecido por $4^{\circ}$ ano técnico. A escola também possui um quadro de funcionários formado por 140 professores e professores e de 37 agentes educacionais.

A biblioteca foi reinaugurada em junho de 2013 - pouco tempo antes de nós realizarmos essa sondagem - após cerca de cinco anos fechada devido a uma reforma. É, atualmente, um espaço em andar térreo, muito agradável, limpa, com boa iluminação (apesar de grades nas janelas) e ventilação e mobiliário em excelentes condições. As cadeiras são azuis e as cortinas, a pintura das paredes e a cor do piso são bastante claros constituindo um ambiente tranquilo que inspira concentração. Há também quadros nas paredes, o que sugere preocupação com o aconchego do ambiente: dois pôsteres de Chaplin e um retrato ilustrado do escritor Fernando Pessoa. O espaçamento permite circular bem entre as estantes, há quatro computadores com acesso à rede de internet, além de doze mesas de leitura à disposição dos alunos. Rigorosamente, em termos de suas condições físicas, o espaço convida 
aos estudos. No entanto, na maior parte do tempo, a biblioteca fica vazia, contando com a presença solitária do bibliotecário, como na imagem abaixo:

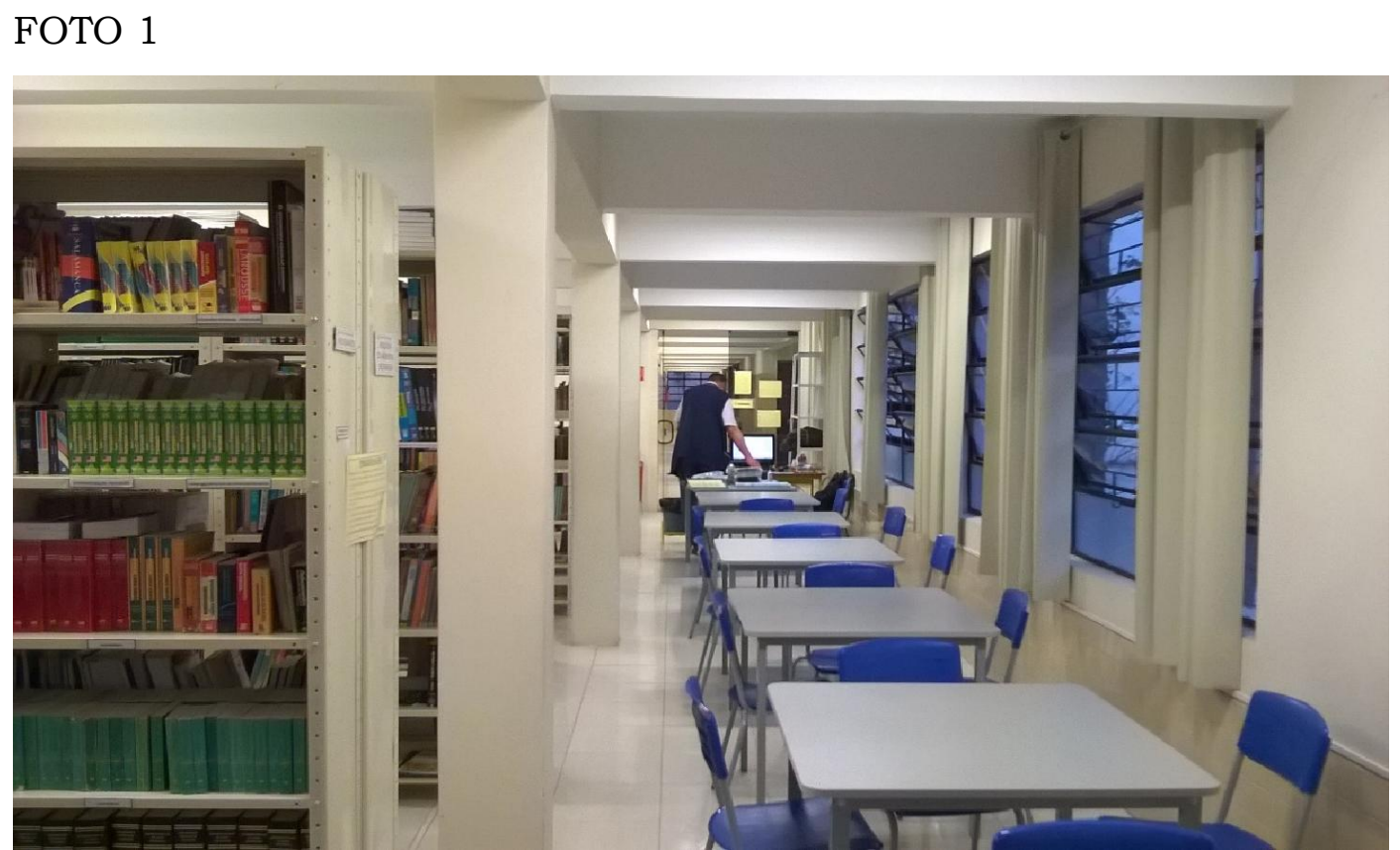

FONTE: AUTORES.

A biblioteca está aberta durante todo o período de aulas nos três turnos: de manhã das 7 h30 até 11 h30, à tarde das 13 h15 até as 17 h e à noite das $18 \mathrm{~h} 50$ até as $22 \mathrm{~h}$. Observemos que embora esteja de portas abertas durante grande parte do dia, a biblioteca não fica disponivel no periodo do intervalo entre os turnos de aula, o que pode resultar em dificuldades para os alunos fazerem dela um espaço de estudos e consultas imediatamente após o fim ou início de suas aulas.

Há, na entrada, avisos que advertem os usuários sobe a organização do ambiente: a necessidade de jogar lixo na lixeira, de colocar cadeiras no lugar, de devolver os livros consultados ao balcão. É proibido o uso dos celulares em seu interior, bem como o consumo de alimentos. Muitos cartazes nas estantes 
pedem silêncio e um aviso alerta para o artigo 331 do código penal que considera crime o desato ao funcionário público no exercício de sua função.

Com efeito, os funcionários que trabalham na biblioteca (cinco) são professores afastados de sala de aula devido à esgotamento mental. O principal deles, que atualmente gerencia a biblioteca e responde pelo atendimento no período noturno, é um professor de Geografia e História formado em Ciências Sociais que deixou a sala de aula após 18 anos de trabalho ininterrupto.

A biblioteca aparece, portanto, como um lugar pouco profissionalizado, cuja gestão não exige conhecimentos especializados e que recebe professores em recuperação, possivelmente em condições muito dificeis na sua relação com a escola e, talvez, com alunos. Como foi relatado por um desses funcionários, os conhecimentos exigidos nas atividades da biblioteca foram desenvolvidos a partir da prática cotidiana. Sempre dentro da regra da tentativa e erro.

Foi essa equipe de professores afastados que identificou e reorganizou o acervo após a reforma. Foi um trabalho hercúleo já que o levantamento constatou que a biblioteca tem aproximadamente 16.000 mil livros divididos em 24 seções e 37 áreas de conhecimento, segundo critérios estabelecidos sem levar em conta nenhum sistema internacional de catalogação.

FOTO 2 


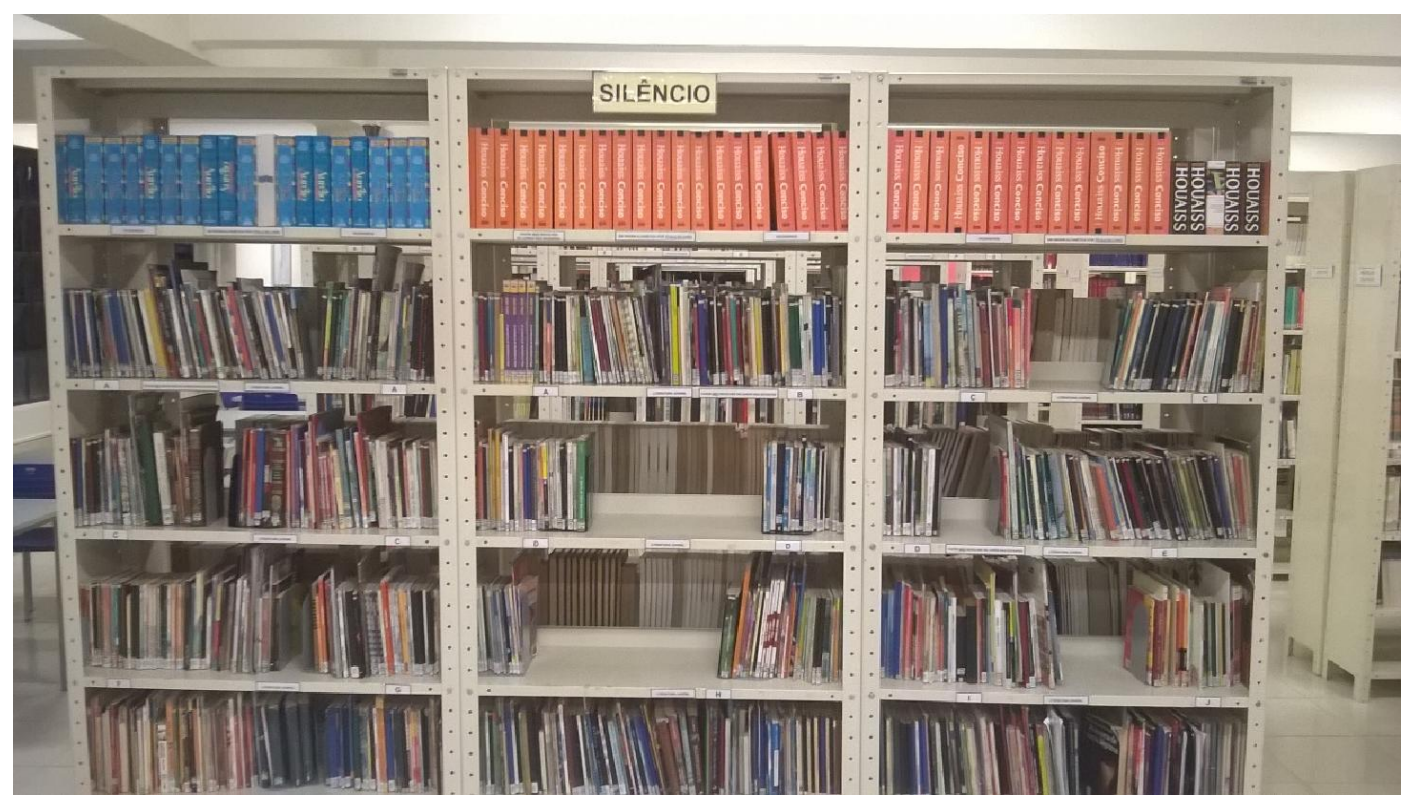

FONTE: AUTORES.

Os exemplares estão organizados e classificados da seguinte maneira: nos corredores 1A, 1B, 2A e 2B são encontrados livros de 'literatura juvenil' e 'literatura universal'. Nos corredores 3A e 3B, encontramos os 'romances estrangeiros, contos e crônicas'. Já as 'novelas, teatros e contos de ficção' compõem as seções 4A e 4B. A seção 5A contém os livros de literatura e poesia'; a 5B, o acervo de 'ciências sociais, psicologia e filosofia'. As 'artes e as biografias' ficam na $6 \mathrm{~A}$ e na $6 \mathrm{~B}$, os livros dos 'cursos técnicos de secretariado e administração'. O acervo de 'história' fica na 7A e 'segurança do trabalho, matemática, física e química' na 7B. Na seção $8 \mathrm{~A}$ ficam os livros de 'direito e informática' e no 8B os de 'pedagogia'. Os livros de 'geografia, de turismo, biologia' ficam na seção 9A e de 'educação física' no 9B. 'Língua portuguesa e dicionários' estão nas 10A e 10B e, para concluir, as 'coleções literárias e os dicionários do CELEN' (Centro de Línguas Estrangeiras Modernas) ficam na seção $11 \mathrm{~A}$ e as 'enciclopédias' na 11B. As seções 12A e 12B são constituídas também por 'enciclopédias e coleções literárias'.

FOTO 3 


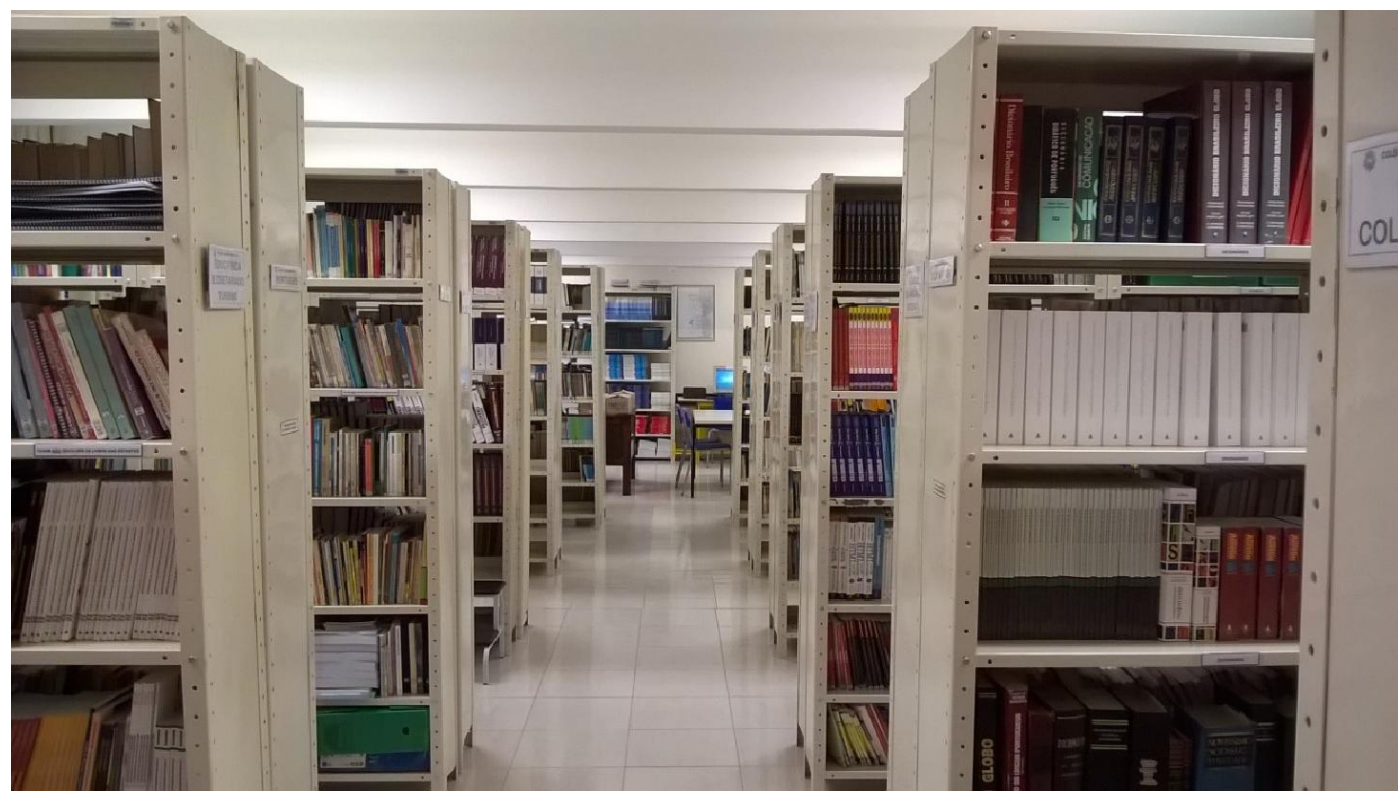

FONTE: AUTORES.

O aluno tem acesso direto ao acervo através das estantes sem que haja um sistema de consulta e localização das obras. Segundo o funcionário, há dois anos a Secretaria de Educação promete a informatização da biblioteca, mas isso não ocorre. O sistema classificatório, bem como a ausência de qualquer sistema de localização do acervo (manual ou informatizado) pode criar dificuldades para encontrar um livro. Afinal não se sabe, por exemplo, se a obra 'Primo Basílio' de Eça de Queiroz será encontrada nas sessões de 'literatura universal', 'romances estrangeiros' ou 'coleções literárias'.

Observamos também que são numerosos os livros didáticos. Na sessão de 'ciências sociais', por exemplo, encontramos 314 livros, dos quais 83 são livros didáticos - sendo 30 exemplares do volume elaborado pela Secretária de Estado da Educação, 28 de Tomazi (2010) e 25 de Bomeny e Freire-Medeiros (2010), ambos aprovados no PNLD Sociologia 2012. Os registros de saídas da biblioteca mostram que os livros didáticos são os mais consultados pelos alunos durante o período de aulas, enquanto que o acervo geral de ciências sociais fica praticamente intocado, com pouquíssimos registros de saída.

Antes que apresentemos mais alguns dados sobre a retirada de livros pelos estudantes, é importante mencionar que, em outubro de 2013 foi também organizado um modesto acervo para uso exclusivo das professoras e 
professores. Fica em um pequeno cômodo ao lado da sala de professores e é conhecida como 'sala da hora atividade' - um espaço exclusivo para o preparo de aulas e provas e correção de atividades que possui duas prateleiras com bibliografia dos cursos oferecidos na escola.

Aqui o acervo é bem menor, composto por aproximadamente 441 divididos segundo as áreas de administração, informática, contabilidade, marketing, direito, economia, gestão de pessoas, pedagogia, secretariado, filosofia e sociologia. São manuais gerais sobre os campos de conhecimento, além de poucas revistas pedagógicas, como a "Carta na Escola". Nas áreas de filosofia e sociologia o acervo é reduzido em comparação com outras áreas de conhecimento como português e matemática. Observa-se, a julgar por esse conjunto de obras a disposição dos professores, que os livros didáticos constituem também uma das ferramentas mais importantes para a realização do trabalho pedagógico.

O fluxo dos empréstimos de livros pelos alunos ao longo do primeiro semestre de 2014 revela dados inquietantes. Foi possível observar que, de janeiro a outubro de 2014, a maioria dos empréstimos foi realizada por estudantes do Ensino Fundamental. Os alunos dos $6^{\circ}$ Anos fizeram 300 empréstimos, ao passo que os estudantes do $7^{\circ}$, realizaram 247 no mesmo período. Os alunos dos $8^{\circ}$ Anos, por sua vez, emprestaram apenas 50 livros e os do $9^{\circ}$ Ano fizeram 57 empréstimos. Observa-se, portanto, uma queda abrupta nos empréstimos dos alunos entre o $7^{\circ}$ e o $8^{\circ}$ anos.

No Ensino Médio foi possível também identificar um quadro de queda no número de empréstimos de livros ao longo da vivência escolar. A situação revelada pelos dados mostrou que, no período na manhã, os alunos do $1^{\circ}$ Ano haviam emprestado somente 26 livros. Já os do $2^{\circ}$ Anos fizeram 36 empréstimos e, por fim, os $3^{\circ}$ anos emprestaram apenas um livro. Para o período da tarde encontramos 31 registros de saídas de livros para os $1^{\circ}$ Anos, 4 para os $2^{\circ}$ Anos e nenhum para os $3^{\circ}$ anos. Para Ensino Médio noturno, os dados mostram 4 empréstimos feitos por alunos dos $1^{\circ}$ Anos enquanto que 17 saídas foram registradas para os $2^{\circ}$ Anos, e 7 para os $3^{\circ}$ Anos. 
Com efeito, os dados revelam que os maiores indices de empréstimos estão entre as turmas que compõem as séries finais do Ensino Fundamental, isto é, os $6^{\circ}$ Anos e $7^{\circ}$ Anos. Este é um dado surpreendente que não apenas reclama aprofundamento da análise, como também aponta para hipóteses incômodas acerca da proporção inversa entre o acúmulo da experiência escolar e o interesse pelo uso da biblioteca escolar.

Especulamos acerca de alguns fatores que concorreram para esse resultado. Ocorre que, nesse período, houve um projeto de leitura para os anos finais do Ensino Fundamental, desenvolvido pelas professoras de língua portuguesa. Esse pode ter sido um fator de impacto positivo que aumentou os empréstimos dos estudantes que participaram dessa ação. Nesse sentido, podemos supor que as professoras de português dos $6^{\circ}$ e $7^{\circ}$ Anos do ensino fundamental vêm conseguindo resultados expressivos com o projeto de incentivo à leitura que, infelizmente, não se estende aos períodos posteriores.

Por outro lado, a acentuada queda dos índices de empréstimos nos anos subsequentes pode ser também explicada pela combinação dos seguintes fatores: aumento no número de tarefas escolares para casa, cobrança por desempenho e falta de interesse e incentivo à leitura. O excesso de atividades escolares nos dois anos finais do Ensino Médio foi sugerido como motivo para a baixa procura da biblioteca em conversas com estudantes. Em particular, alunos do $3^{\circ}$ Ano disseram que sofrem elevada pressão para aprovação no vestibular, ficando, por isso, menos na escola.

Nessa perspectiva, parece que as tarefas e estudos não estimulam o uso da biblioteca escolar, nem a permanência na escola, mas antes favorecem seu afastamento. De qualquer modo, isso deve ser investigado porque parece apontar para o fato de que 'a escola atrapalha os estudos'.

No entanto, cabe também considerar o fato de que a falta de frequência à biblioteca escolar e a baixa retirada de livros não permite concluir, de imediato, o desinteresse ou falta de leitura dos estudantes.

Afinal, há outros meios para aquisição e empréstimo de livros. De qualquer modo, os dados alcançados através de nossas observações precisam ser explorados de modo mais consequente inquirindo alguns dos fundamentos 
que levam ao interesse pela biblioteca escolar. Nesse sentido, a conclusão desse texto, pelo que tem de provisório, trata de especular sobre algumas hipóteses e fatores que possibilitam o quadro atual de escassez e decréscimo dos empréstimos a cada ano escolar. Ao menos foi isso que as fontes consultadas nos mostraram num primeiro momento.

\section{Algumas hipóteses e desafios}

Essa investigação, ainda que preliminar, nos permite constatar que há grandes expectativas em relação aos benefícios da biblioteca escolar que se expressam em documentos diversos de diferentes instituições nacionais e internacionais. As ideias em favor da biblioteca escolar constituem o fundamento de ações políticas sistemáticas de apoio à aquisição de acervo que, no Brasil, tem se expandido desde a década de 2000.

Não obstante, através da consulta dos registros de empréstimo da biblioteca da escola analisada, constatamos que ocorre subutilização de seu acervo, bem como de seu espaço. Além disso, há uma queda significativa nos empréstimos à medida que o aluno avança para os anos finais do Ensino Fundamental e, em particular, para o Ensino Médio.

O nosso trabalho sugere, portanto, a seguinte situação: o valor da biblioteca escolar é reconhecido, livros estão chegando, são catalogados e registrados no sistema, mas isso não significa imediatamente melhor uso do seu espaço, nem repercussão positiva no empréstimo de livros.

Faremos aqui um elenco dos elementos que parecem compor esse fenômeno e que consideramos aqui, diante do caráter provisório dessa análise, como parte de um esforço de formulação de hipóteses para pesquisas futuras: I. A biblioteca foi aberta muito recentemente após ficar fechada por um longo período (cinco anos). Devemos, pois, lembrar que cinco anos no ciclo escolar corresponde a uma geração inteira de alunos do ensino médio que ficaram durante todo o período do ensino fundamental sem acesso à biblioteca escolar. Se considerarmos a frequência à biblioteca como um hábito desenvolvido a partir de certas condições favoráveis, a reabertura não será suficiente para 
que a biblioteca seja novamente (ou ineditamente) vista como parte constitutiva da rotina escolar. Nesse sentido, embora a biblioteca reformada tenha instalações físicas adequadas aos estudos, seu uso sistemático parecer exigir ações que favoreçam a sua incorporação como o principal espaço de estudos autônomos, cuja frequência pode ser atividade regular de estudantes. II. Observamos três fatores organizacionais que podem criar dificuldades para esforços de formação de leitores e de constituição da biblioteca como espaço privilegiado de estudos, em particular para consulta e empréstimo do seu acervo: a) a falta de recursos (informatizados ou manuais) de busca ao acervo; b) os critérios (pouco legiveis) de classificação dos livros e, c) por fim, os horários da biblioteca não são favoráveis porque, apesar de aberta durante longas horas durante o dia e a noite, ela fecha nos intervalos entre os turnos, impedindo que os alunos acessem o espaço e seu acervo pouco antes ou pouco depois das aulas.

III. A biblioteca é vista, portanto, como um espaço que funciona apenas em horários homólogos às aulas, além de não ter profissionais especializados na gestão de seu acervo e no atendimento aos usuários. Não apenas não há especialistas dedicados à organização, classificação e implementação de mecanismos de busca ao acervo segundo critérios mais claros, como também sua equipe é composta por profissionais docentes que se encontram afastados de suas funções originais, em situações, via de regra, muito delicadas de identificação com seu ofício e com o ambiente escolar. Ainda que possa ser um lugar de pertencimento interessante para restituir os fios e a trama que os relaciona à docência e aos alunos, não podemos excluir a hipótese de que, por meio desse procedimento, no imaginário escolar, se constitui a ideia de que a biblioteca escolar é um lugar desprestigiado, para a qual são encaminhados professores esgotados pelo trabalho. É o lugar onde ocorre uma espécie de exílio forçado da rotina escolar. Não obstante, se reconhece que, para o êxito da biblioteca escolar é necessário que ela se consolide como um locus de ação de profissionais especializados em gestão da informação e também de pessoas em condições favoráveis para atuar como transmissores da leitura. Petit (2008, p.166) já assinalou acerca da importância de 
bibliotecários e professores na transmissão do amor pela leitura e na identificação dos gostos dos alunos: ... não é a biblioteca nem a escola que desperta o gosto por ler, por aprender, imaginar, descobrir. É um professor, um bibliotecário que, levado à sua paixão, a transmite através de uma relação individual. Vale, nesse sentido, mencionar que um estudo de caso numa escola muito semelhante a essa que analisamos - mas com acervo organizado segundo padrões que facilitam a localização dos exemplares e onde houve mudanças no sentido de um atendimento individualizado dos usuários constatou-se, num curto período de tempo, aumento sensivel da frequência à biblioteca e do empréstimo de livros. (MALHADAS, 2014, 32). Isso nos faz, ao menos considerar a possibilidade de que a ação dos bibliotecários e demais profissionais da biblioteca pode favorecer o acréscimo de empréstimos.

IV. Não obstante, não é possivel compreender a formação de leitores apenas a partir de ações no interior da própria biblioteca. Há também ações mais abrangentes, em sala de aula, que podem estimular a leitura. Vimos que, possivelmente, um programa de leitura nos anos finais do Ensino Fundamental teve impacto favorável nos empréstimos e isso reforça a hipótese de que algumas estratégias e programas escolares podem favorecer a leitura. Práticas escolares devem, pois, estimular e favorecer o uso rotineiro da biblioteca e a prática da leitura. Sabemos que o uso da biblioteca não é a única forma de reconhecer a capacidade da escola em despertar interesse pelo repertório intelectual e científico produzido pela sociedade. De todo modo, trata-se de uma modalidade de ingresso ao mundo do conhecimento formal, indicador do domínio de códigos importantes para a experiência intelectual autônoma em nossa sociedade: as formas de busca, a leitura e interpretação das referências, o entendimento dos critérios de classificação, a hexis corporal no uso de seus espaços e na circulação por suas estantes, o desenvolvimento do senso de relevância na seleção de obras, etc. Nesse sentido, ir à biblioteca é, afinal, uma atividade que exige adesão dos individuos a padrões de comportamento muito específicos, inclusive o autoconhecimento e o desenvolvimento do 'gosto' diante de uma fortuna intelectual muito ampla. Ser usuário de uma biblioteca pode ser considerado uma carreira no sentido dado 
ao termo por Becker (2008, p. 32), pois compreende uma sequência de atos apreendidos que devem ser interiorizados de modo sistemático como uma atividade regular. Nesse sentido, as políticas dedicadas à qualificação e ampliação do acervo de bibliotecas escolar devem corresponder a uma preocupação com a constituição, em toda a prática educativa, da biblioteca como um 'lugar' dos alunos, menos regulado do que a sala de aula, mas onde se aprende técnicas universais de acesso ao acervo ao mesmo tempo em que se pode dispor de um atendimento individualizado. Ou seja, rotina, técnica e artesanal das relações parecem ser ingredientes para uma política pública favorável à formação de leitores.

V.Com efeito, não podemos deixar de observar que a discussão sobre a leitura e o uso de bibliotecas escolares passa também pela crítica sociológica ao sistema de ensino. Essa seria a base de uma sociologia da leitura que anda de mãos dadas com a sociologia da educação e que encontra em Anne Marie Chartier uma de suas principais pesquisadoras. Estudos empíricos de Chartier (1995) realizados sobre a formação de novos leitores na França identificaram correlação estatística entre elevada origem social e interesse pela leitura, tal como foi pesquisado por Bourdieu e por Passeron (2014). Assim, seria possivel afirmar que a familiaridade com os livros e a leitura é processo de aprendizagem que dependeria de um contexto social abrangente que ultrapassa a vivência escolar. (CHARTIER, 1995, p.25). Diante disso, Chartier (1995, p.28) conclui que, para ensinar as crianças a ler de fato, seria preciso mudar práticas escolares considerando estas desigualdades. Para a autora, a escola precisa "descolarizar" o ato de ler incentivando antes o "gesto de leitura" (como, por exemplo, o manuseio de livros, artigos de jornais e bulas) do que a formação de um "gosto pela leitura." (1995, p.28). Nesse sentido, a autora propõe uma politica pela leitura que a constitua menos como uma atividade intelectual do que uma atividade sensorial e prática.

VI. Podemos aqui pensar em mais um elemento para nossa análise, que não se refere ao uso da biblioteca nem às ações educativas mais formais, mas ao sentido da leitura ao longo dos anos escolares. Na verdade, levado ao limite, 
este novo argumento exige uma reflexão sobre os fundamentos do conhecimento escolar e a sugestão de que 'a leitura' e 'os estudos' se opõe, conforme ficou sugerido no relato de alguns alunos e alunas. Embora a escola seja reconhecida como agente principal de incentivo à leitura (sendo muitas vezes mais influente que os pais), há constatações de que as demandas formais do saber escolar podem também desfavorecer o gosto pela leitura. É o que sugere Petit (2008, p.155) que nos diz que é possível considerar que, quando a leitura se aproxima de uma abordagem erudita e utilitária para fins escolares, o leitor pode perder o gosto pelos livros. Pennac (1997) também considera esse efeito desfavorável do conhecimento escolar capaz de afastar o leitor do prazer da leitura. Nesse sentido, nos parece importante ao menos levar em conta esse elemento como algo constitutivo do fenômeno que analisamos, caracterizado pelo notável decréscimo do empréstimo de livros a cada ano escolar. Essa perspectiva implica o procedimento de planejar ações escolares que reconheçam não apenas a dimensão sensorial e útil destacada por Chartier, mas também a dimensão imaginativa da leitura.

\section{Considerações finais}

Levando em conta o caso particular de uma biblioteca escolar, procuramos refletir sobre as expectativas e os usos desse espaço. Principalmente no que tange os sentidos e práticas escolares que orientam o acesso a livros, o incentivo à leitura e a formação de leitores. Ao final, deixamos algumas hipóteses e reflexões sobre o lugar e a importância que a biblioteca escolar pode exercer no cotidiano dos jovens estudantes.

Concordando com Petit (2008, p.13) “a leitura permite abrir um campo de possibilidades, inclusive onde parecia não existir nenhuma margem de manobra" a biblioteca constitui-se em um campo de possibilidades de vivencia, ensino e aprendizado, complementares aos currículos escolares.

A valorização das suas expectativas e o reconhecimento dos seus usos

é uma prática que precisa ser fomentada por funcionários, professores e 
alunos. Nessa perspectiva, a formação de novas e novos leitores será o resultado de um trabalho pedagógico desenvolvido coletivamente.

Por fim, nosso objetivo foi contribuir com o debate sobre bibliotecas escolares a partir de um olhar sociológico, sensivel as práticas sociais de incentivo, acesso e valorização da leitura.

\section{Referências bibliográficas}

BALÇA, Ângela, FONSECA, Maria Adelina (2012), "Os docentes e a biblioteca escolar: uma relação necessária", Revista Lusófona de Educação, n 20, pp.65-80,[Consult. a 16.06.2013].Disponivel

em:< http://revistas.ulusofona.pt/index.php/rleducacao/article/viewFile/2938/2213>.

BECKER, Howard Saul. (2008), Outsiders. Estudos de sociologia do desvio, Rio de Janeiro, Editora Zahar.

BOMENY, Helena, FREIRE-MEDEIROS, Bianca (2010), Tempos modernos, tempos de sociologia, São Paulo, Editora do Brasil.

BOURDIEU, Pierre, PASSERON, Jean-Claude (2014), Os herdeiros: os estudantes e a cultura, Tradução Ione Ribeiro Valle, Nilton Valle, Florianópolis, Editora da Universidade Federal de Santa Catarina.

BRASIL. Lei $\mathrm{n}^{\circ} 12.244 / 2010$, de 24 de maio, Lei que dispõe sobre a universalização das bibliotecas nas instituições de ensino do País.

BRASIL, Lei $\mathrm{n}^{\circ}$ 9394/1996, de 20 de dezembro, Lei que estabelece as diretrizes $e$ bases da educação nacional.

BRASIL, Resolução $\mathrm{n}^{\circ} 7 / 2009$, de março, Resolução que dispõe sobre o Programa Nacional Biblioteca da Escola (PNBE).

CHATIER, Anne-Marie (1995), "Leitura escolar. Entre a pedagogia e sociologia", Revista Brasileira de Educação, n ${ }^{\circ}$ 0,p. 17-52, Set./Out./Nov./Dez, [Consult. a 04.10.2015].Disponível em: <http://anped.org.br/rbe/rbedigital/rbde0/rbde0_04_anne-marie_chartier.pdf>

INSTITUTO DE PESQUISA E PLANEJAMENTO URBANO DE CURITIBA (2010), Matriculas nas escolas da Rede Municipal de Ensino, por modalidade de ensino ofertada, segundo escolas, na Regional Portão, [Consult. a 02.06.2015]. Disponível em:<http://curitibaemdados.ippuc.org.br/anexos/2010_Matr\%C3\%ADculas\%20na 
s\%20Escolas\%20da\%20Rede\%20Municipal\%20de\%20Ensino,\%20Segundo\%20o\%2 0N\%C3\%BAcleo\%20Regional,\%20em\%20Curitiba.xls>.

DAMASCENO, Andreia Cristina, MESQUITA, José Marcos Carvalho (2014), "Atributos determinantes da baixa utilização de bibliotecas: estudo em uma instituição de ensino pública federal", Perspectivas em Ciência da Informação,v.19,n.1,p.149-169,jan./mar.,[Consult.a 16.06.2015].Disponivel em: <http://www.scielo.br/readcube/epdf.php?doi=10.1590/S1413993620140001000 10\&pid=S141399362014000100010\&pdf_path=pci/v19n1/10.pdf\&lang=pt>.

FERRAREZI, Ludmila, ROMÃO, Lucília Maria Sousa (2013), "Certos Sentidos de Biblioteca Escolar: Efeitos de Repetição e Deslocamento", Linguagem em (Dis)curso , Tubarão, Santa Catarina, v.13,n. 1, p.35-64, jan./ abr.,[Consult. a 16.06.2015]. Disponivel

em:<http://www.scielo.br/readcube/epdf.php?doi=10.1590/S15187632201300010 0003\&pid=S1518-

76322013000100003\&pdf_path=ld/v13n1/a03v13n 1.pdf\&lang=pt>.

LAJOLO, Marisa (2012), "Livros, leitura e literatura", in Zoara Failla (org.). Retratos da Leitura no Brasil. volume 3, Parte I, pp. 163-181, [Consult. a 06.06.2015]. Disponivel em:

http:// prolivro.org.br/images/antigo/4095.pdf.

MALHADAS, Paula Augusta. Assumpção ( 2014), Programa Nacional da Biblioteca na Escola 2011: um estudo de caso, Monografia de conclusão do Curso de Letras, Curitiba, Setor de Ciências Humanas, Letras e Artes da Universidade Federal do Paraná.

MINISTÉRIO DA EDUCAÇÃO, FUNDO NACIONAL DE DESENVOLVIMENTO DA EDUCAÇÃO, (2014), Programa Nacional Biblioteca da Escola, [Consult. a 10.08.2014]. Disponivel em: <http://www.fnde.gov.br/programas/biblioteca-daescola/biblioteca-da-escola-apresentacao $>$.

MINISTÉRIO DA EDUCAÇÃO/INSTITUTO NACIONAL DE ESTUDOS E PESQUISAS EDUCACIONAIS ANÍSIO TEIXEIRA (2014), Censo Escolar, [Consult. a 31.10.2015].Disponivel em: <http://portal.inep.gov.br/basica-censo>.

PENNAC, Daniel (1997), Como um romance. Rio de Janeiro, Editora Rocco.

PETIT, Michèle (2008), Os jovens e a leitura: uma nova perspectiva, São Paulo, Editora 34.

SECRETÁRIA DE ESTADO DA EDUCAÇÃO, Núcleo Regional de Educação de Curitiba, (2010), Projeto politico pedagógico do Colégio Estadual Pedro Macedo - Ensino Fundamental, Médio e Profissional, Curitiba - PR.

SILVA, Ezequiel Theodoro. (2012), “A escola e a formação de leitores” in Zoara Failla(org.). Retratos da Leitura no Brasil, volume 3, Parte I,pp.107-116,[Consult.a 06.06.2015]. Disponivel em: http://prolivro.org.br/images/antigo/4095.pdf. 
TOMAZI, Nelson Dacio (2010), Sociologia para o ensino médio, $2^{\circ}$ edição, São Paulo, Editora Saraiva.

UNESCO/IFLA (2002), Directrizes da IFLA/UNESCO para Bibliotecas Escolares, versão em português (Portugal), 2006, tradução Maria José Vitorino, [Consult. a 04.11.2015].Disponivel em: <http://www.ifla.org/files/assets/school-librariesresource-centers / publications/school-library-guidelines/school-library-guidelinespt.pdf>. 